Supporting Information

\title{
Carbon doped vanadium nitride used as cathode of high-performance aqueous zinc ion batteries
}

Qingsong Su${ }^{\mathrm{a}}$, Yao Rong ${ }^{\mathrm{a}}$, Hongzhe Chen ${ }^{\mathrm{a}}$, Jian $\mathrm{Wu}^{\mathrm{a}}$, Zhanhong Yang, ${ }^{\mathrm{a},{ }^{*}}$, Lie Deng ${ }^{\mathrm{a}}$, Zhimin $\mathrm{Fu}^{\mathrm{a}}$

a Hunan Province Key Laboratory of Chemical Power Source, College of Chemistry and Chemical Engineering, Central South University, Changsha, 410083, China

b Innovation Base of Energy and Chemical Materials for Graduate Students Training, Central South University, Changsha, 410083, China

*Corresponding author. E-mail address: zhyangcsu611@163.com (Z. Yang). 


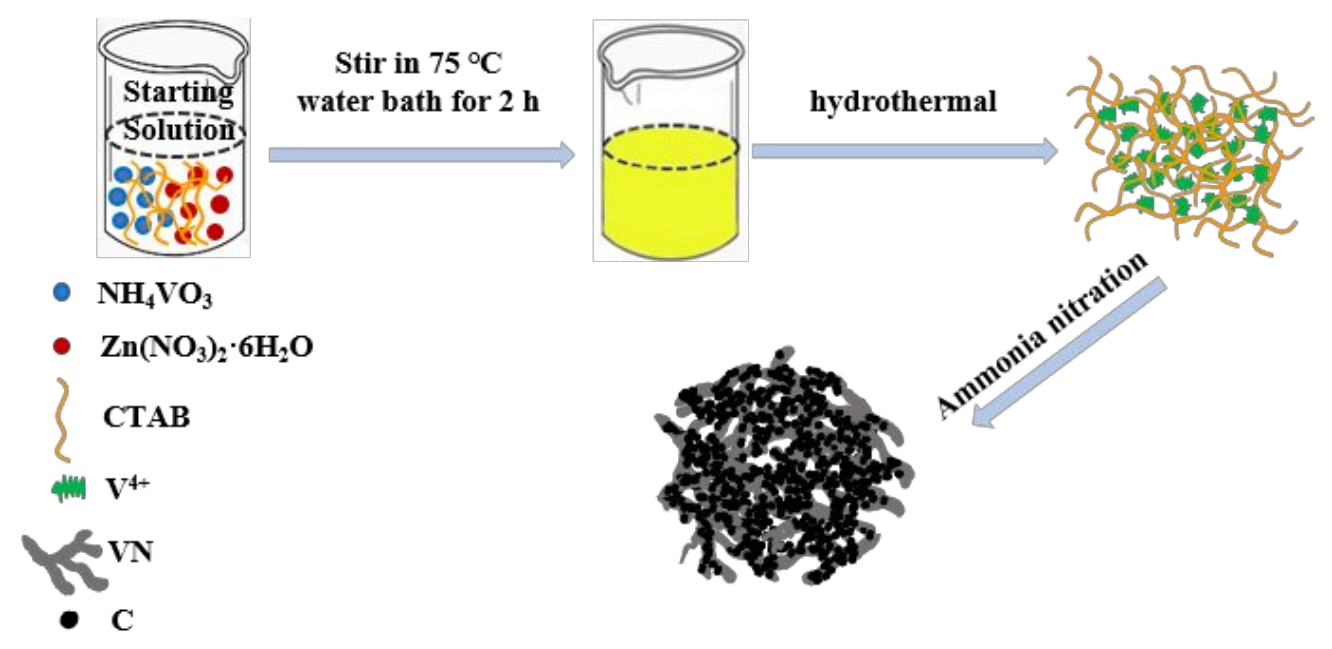

Figure S 1. Synthesis process of the coral VN/C

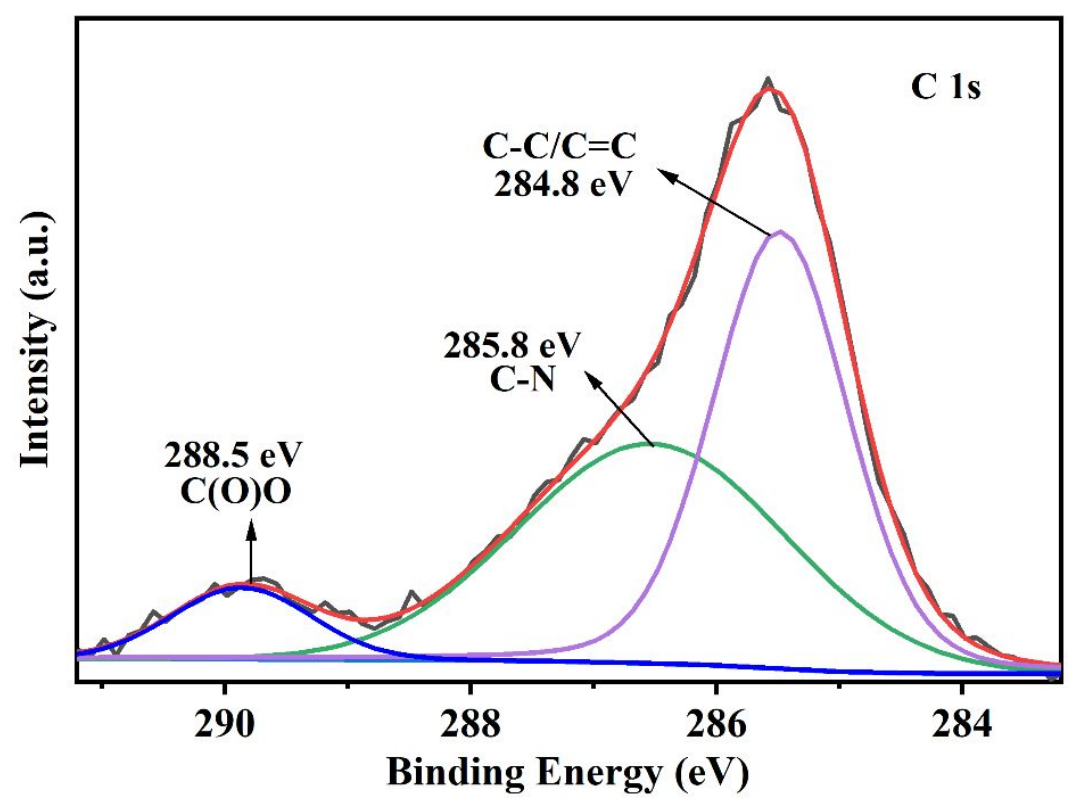

Figure S 2. XPS spectra coral VN/C: C 1s spectrum 


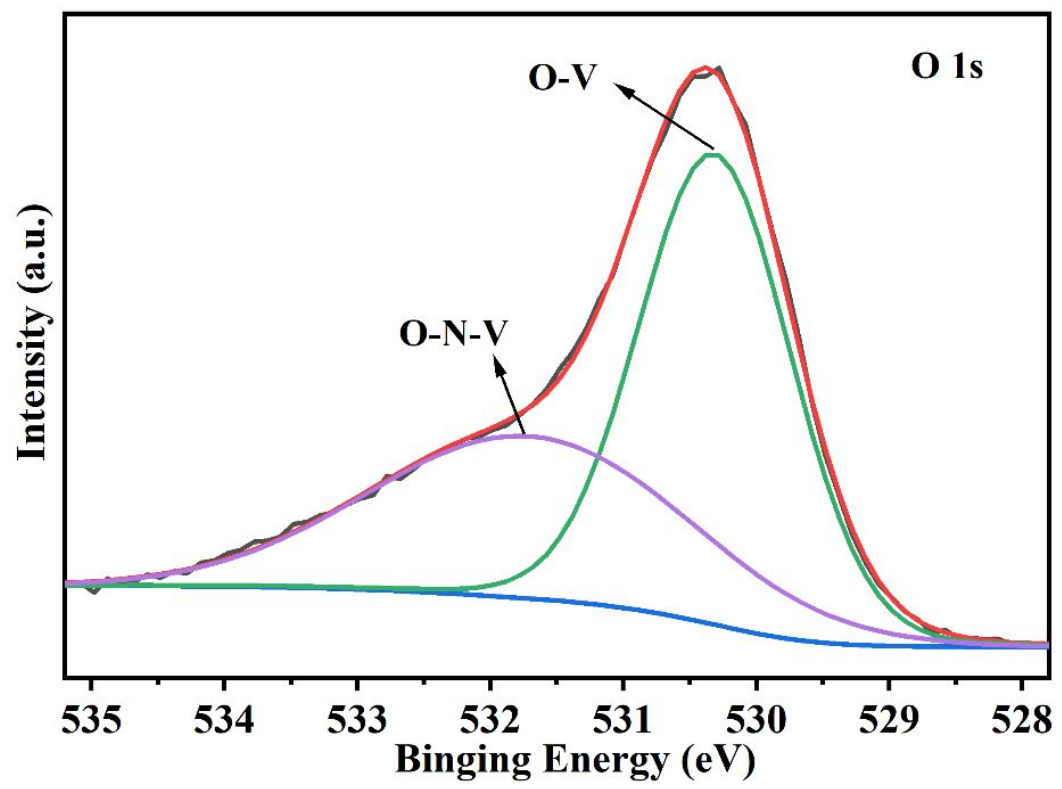

Figure S 3. XPS spectra coral VN/C: O 1s spectrum 


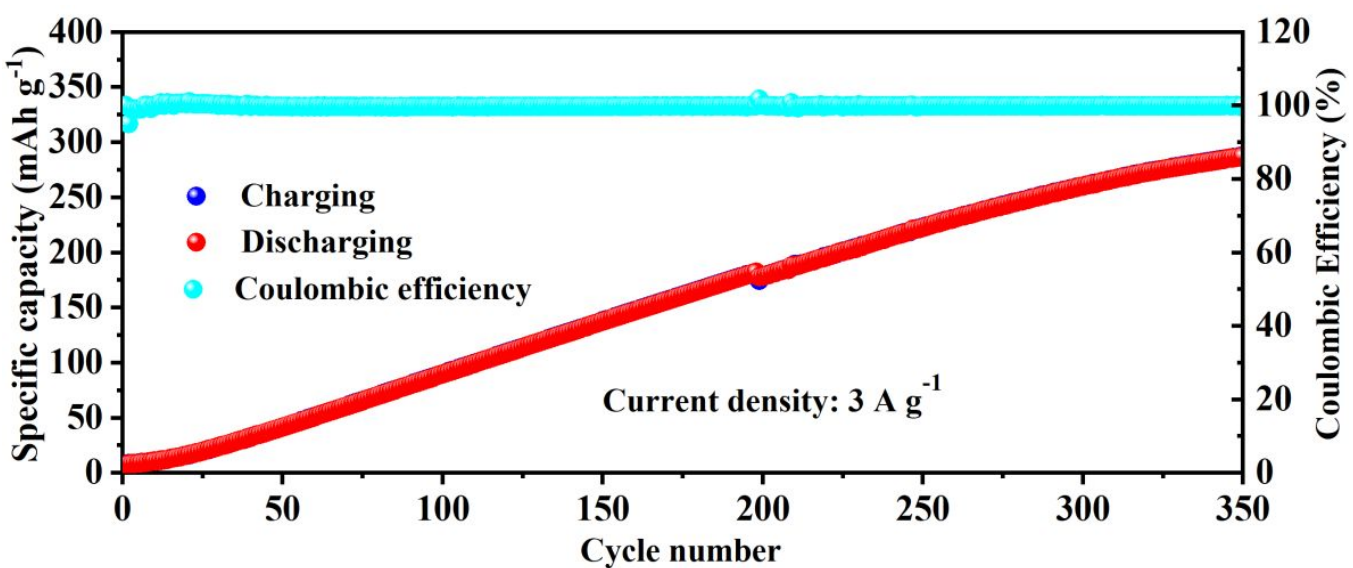

Figure S 4. Activation curve of coral VN/C at $3 \mathrm{~A} \mathrm{~g} \mathrm{~g}^{-1}$ current density

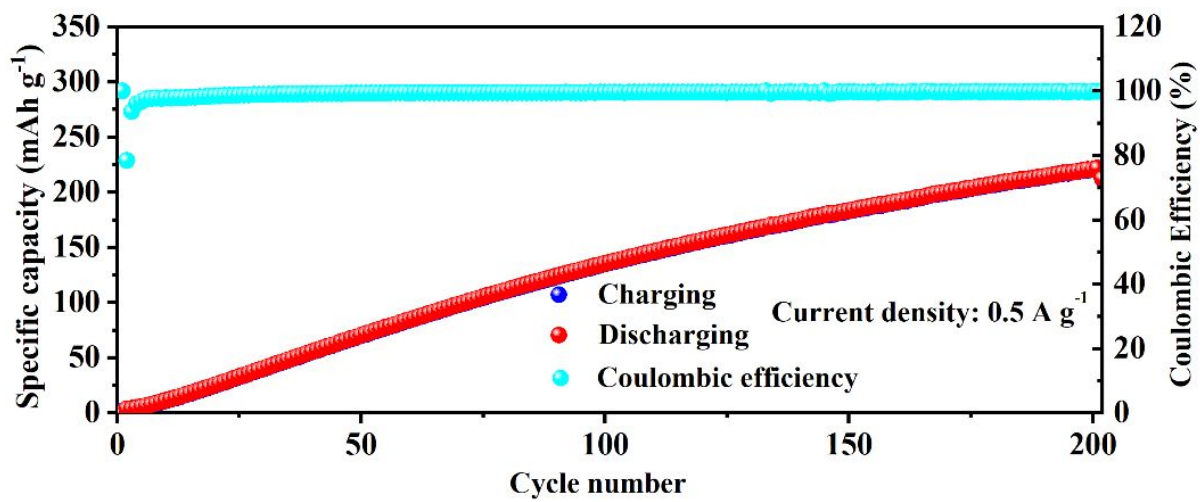

Figure $\mathrm{S} 5$. Activation curve of $\mathrm{VN} / \mathrm{C}$ at $0.5 \mathrm{~A} \mathrm{~g}^{-1}$ current density 


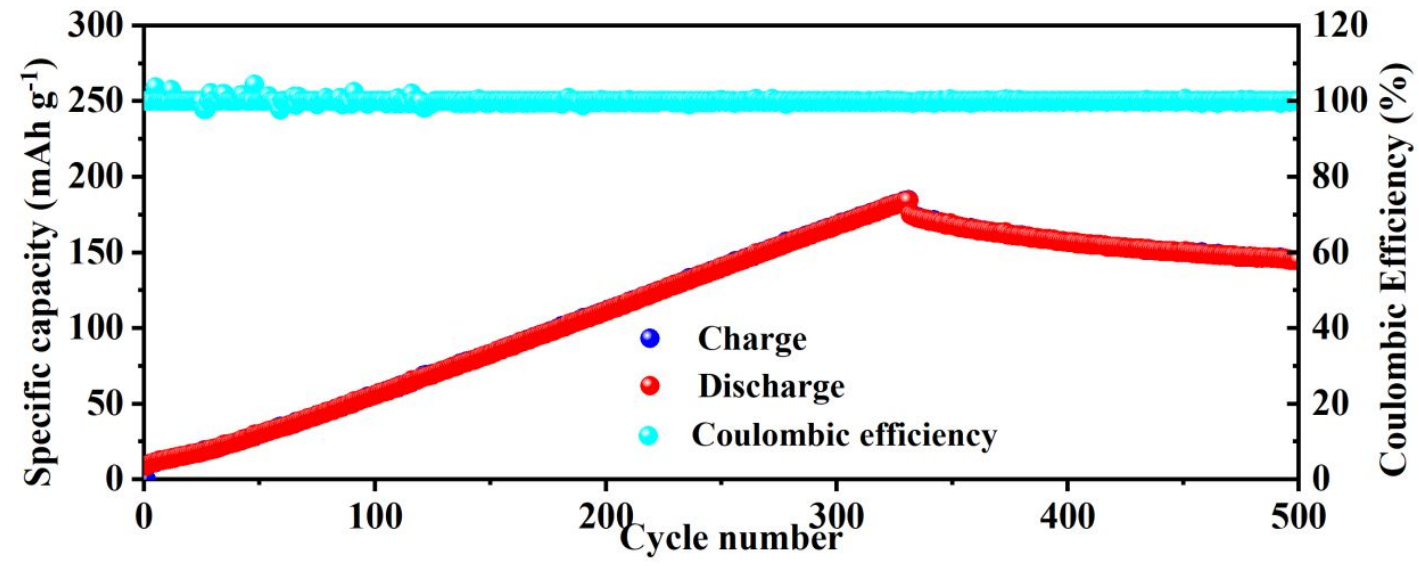

Figure S 6. Activation curve of coral VN/C at $15 \mathrm{~A} \mathrm{~g}^{-1}$ current density

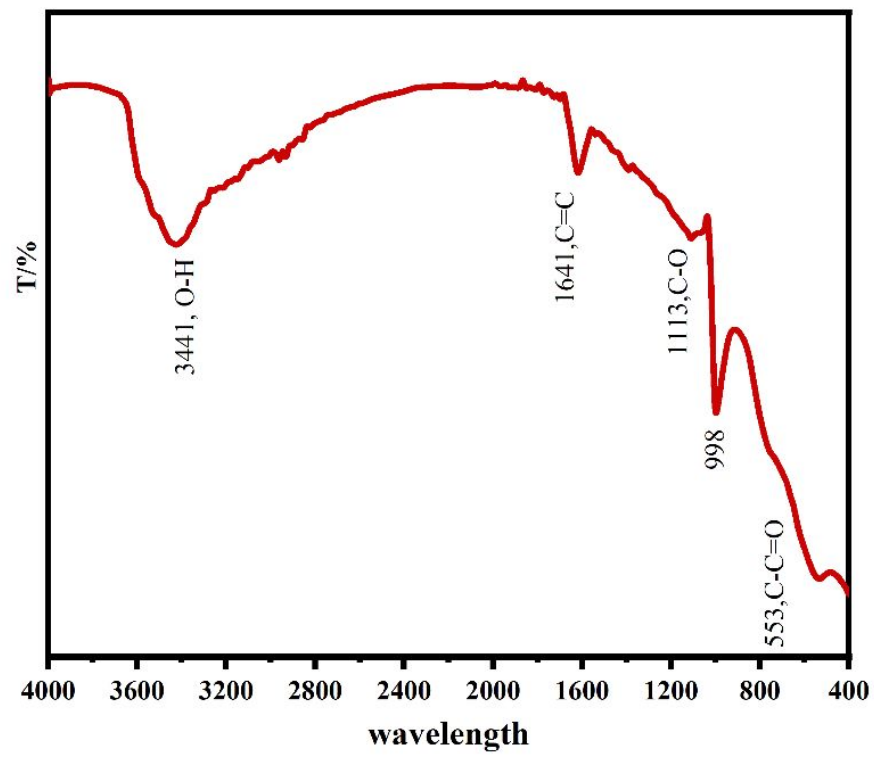

Figure S 7. the infrared Spectroscopy of C on coral VN/C 